\title{
Positivist Misconceptions of Science and the Search for Viable Solutions
}

\author{
Ivan Chompalov \\ Edinboro University of Pennsylvania, \\ Pennsylvania, U.S.A. \\ Lubomir Popov
}

Bowling Green State University, Ohio, U.S.A.

\section{Abstract}

Prevailing current definitions of science are largely based on a traditional, positivist paradigm that favors the natural sciences and either denies or downplays the scientific status of the social sciences and the humanities. The disciplinary organization and institutionalization of research and systematic inquiry is still the norm. This article argues that the rigid organization of science and indeed the dominant view that there are hard sciences and soft sciences with the latter occupying an inferior position with regard to their knowledge claims and utility is pretty outmoded and does not fit well the current challenges and global needs. This is not just an academic issue but has clear practical implications in terms of funding and staffing, as well as the distribution of other valuable resources, especially in view of the dwindling federal and state funding for both the natural sciences and the humanities and social sciences. We develop our argument using as a methodological platform the ideas of 'The Two Cultures,' the 'Science Wars,' the new constructivist turn in social studies of science, and science as a social institution. We argue that current definitions of science need to be modified to include the humanities and to emancipate the social sciences and the 'soft' paradigms associated with them. This can form the basis of an earnest effort for better integration of different kinds of disciplines and for achieving much needed synergisms to tackle complex problems that tend to be multifaceted and whose solutions do not easily conform to single disciplinary paradigms. The contention here is that such a bridge between the two cultures can use as a model the social sciences, since they successfully combine methods from the natural sciences with approaches and theories common in the humanities. In our opinion, this is a feasible path to both greater interdisciplinarity and more vigorous collaboration between the different branches of science that can benefit both working scientists and society at large when dealing with pressing issues like 
environmental problems, the depletion of natural resources, pandemics, and natural disasters.

Keywords: philosophy of science, organization of science, interdisciplinarity, soft paradigms, humanities

\section{Introduction}

We are facing numerous problems and challenges that need a collective effort on both a global and national level. An incomplete list would include global warming, environmental destruction and pollution, terrorism, war, epidemics and pandemics, inequality and poverty, resource shortages, economic crises, instability, and a host of others. Typically, these problems are complex and multifaceted. They do not lend themselves to simple solutions based on a single discipline or specialty, but instead require concerted efforts and collaboration among experts from multiple fields of research, as well as some degree of interdisciplinarity.

Take for example global warming. It definitely has important aspects whose understanding requires findings and explanations provided by the natural sciences (meteorology, chemistry, physics, biology, and certain engineering fields). But it also requires valid and reliable knowledge provided by the social sciences and humanities pertaining to social communities' and individuals' coping with and adaptation to their changing environment (sociology, economics, psychology, history, anthropology, etc.).

Given this reality, it is surprising that what counts as science and what is considered scientific is still largely based on a traditional, positivist paradigm that heavily leans towards the natural sciences and either denies or downplays the scientific status of the social sciences and the humanities. The disciplinary organization and institutionalization of research and systematic inquiry is still the norm and the division between "in-groups" and "out-groups" is pretty much alive.

This paper argues that the rigid organization of science and indeed the dominant view that there are hard sciences and soft sciences with the latter occupying an inferior position with regard to their knowledge claims and utility is pretty outmoded and does not fit well the current challenges and global needs. This is not just an academic issue but has clear practical implications in terms of funding and staffing, as well as the distribution of other valuable resources, especially in view of the dwindling federal and state funding for both the natural sciences and the humanities and social sciences.

This continuing duality and chasm between natural sciences and humanities has been reflected in the concept of the 'two cultures' initially developed by C.P. Snow in the late 1950s, which argues that these are two separate worlds that are largely incommensurate with each other and unfamiliar with one another. He considers this 
polarization a sheer loss to society, a loss that is practical, but also intellectual and creative. Snow (1959) himself was hoping in his later writings for a bridge between the two cultures of science and literary endeavors or at least for a reasonable dialogue. He was keenly aware of the potential for doing so, being himself a scientist by training and a writer by vocation, although he did not elaborate the concrete mechanisms through which this might happen (Snow, 1959).

We believe that some type of integration has already been attempted on a smaller scale with interdisciplinarity and creative approaches to some problems (e.g., urban planning, human-computer interaction), but these are clearly the exceptions rather than the rule. It is still more common to try to protect your own turf, to set clear demarcation lines not only between the sciences and humanities, but within each of these domains. Even the right to study one domain by researchers from the other is questioned or dismissed outright. A fairly recent example of this are the so-called "science wars" that raged in the 1990s and early 2000s.

Interestingly enough, there was no substantial criticism by the natural scientists of sociology of science or of science and technology studies more generally so long as these adhered to a positivist model of science. That was the case in the early days of sociology of science associated with the works of its founder Robert Merton (1973). Sociology of science as a systematic study of the social institution of science took off in the 1960s and its emergence is generally credited to the works and investigations of Robert Merton. His sociology of science, a.k.a. "traditional sociology of science" or "the positivist and normative study of science" has several distinctive features. Science is perceived as a rational enterprise, where the content of the natural sciences is ultimately determined by facts of reality. There are clear lines of demarcation between science and non-science. For Merton (1973), the content of science is a "black box" and this content and the intellectual side of science is better left to historians of ideas and philosophers of science. Science is somewhat autonomous and unique among other human endeavors and scientific research is governed by a particular social structure at the heart of which is the "scientific ethos," which consists of observing the following four norms: communism; universalism; disinterestedness; organized skepticism.

It was not until the so-called "constructivist and interpretivist turn in social studies of science" that severe criticisms and rejection were voiced by a number of natural scientists that eventually culminated in the "science wars." The turn itself happened in the 1970s and was jumpstarted by the historian of science Thomas Kuhn, whose seminal book "The Structure of Scientific Revolutions" (1970) sent shock waves through the field of social studies of science (Chompalov \& Popov, 2014). His ideas about "paradigm," "incommensurability," "normal science", and "scientific revolution" spurred a new wave of social studies of science that tried to demonstrate empirically that knowledge claims are relative and incommensurable and that all data are ultimately theory-laden. The proliferation of new science studies theories and 
approaches were stimulated by this new paradigm. Postmodernist critiques and feminist approaches argued that far from being objective and impartial, science is essentially a socially constructed activity and hence should be treated no better or worse than other knowledge claims. This new constructivist turn was in turn noticed and severely taken to task by natural scientists. A group of those scientists criticized the social studies of science in their new form as essentially being unscientific and an example of how to let politics undermine the authority and reputation of science. The social scientists themselves responded by accusing natural scientists of hubris, lack of an earnest effort to evaluate alternative claims, partisanship, and obfuscation of the real issues.

In all of this, one thing became clear-the two cultures were as far apart as ever and unwilling to look for overlap, synergies, and integration of some of the opposing approaches. Snow's hope of a bridge between the two was certainly dashed. The present paper makes the argument that, although some interdisciplinary efforts have proven successful, these are few and far between and typically happen within one of the cultures (e.g., biochemistry or biotechnology) and juxtaposition has actually been worsened by the "science wars." A more natural and already existing bridge between the two cultures is provided by the social sciences that combine elements of both science and the humanities in the way they are practiced now. Just like the natural sciences, the social sciences often use quantitative methods, such as experiments, surveys, polls, systematic observations to collect data. They also employ random sampling for selection of units of analysis and various statistical techniques to carry out rigorous analysis and hypothesis testing. On the other hand, similar to the humanities they sometimes resort to qualitative methods, such as participant observation, interviews, field research, and content analysis, interpretation and hermeneutics. Recently, mixed methods of research that blend the quantitative with qualitative modes of investigation have gained traction in the social sciences. Finally, we discuss the implications and potential of integrating scientific and humanitarian methods for deeper understanding of complex phenomena and their tentative benefits for the public at large.

\section{Definitions of Science: Problems and Queries}

Most definitions of science are heavily based on the typical, positivist image associated with the natural sciences. On common way to define science is given by the Collins Online English Dictionary (2020): The systematic study of the nature and behavior of the material and physical universe, based on observation, experiment, and measurement, and the formulation of laws to describe these facts in general terms. There are several problems with this definition. First, it obviously considers as science only the natural sciences and excludes any other form of systematic inquiry, since it mentions just "the material and physical universe." What about the social world and human nature? Apparently, according to this widespread view, they don't qualify as valid objects of research to be considered scientific endeavors. 
Second, the methods used in science are the observation and the experiment and a scientific activity should involve some kind of measurement. Again, this seems to be too restrictive and excludes, for example, some widely used methods in sociology that lead to a systematic collection of data that can then be analyzed to either test hypotheses or find patterns and thus amounts to doing science. There are the survey, unobtrusive measures, analysis of documents, secondary data analysis, various forms of the interview, and different modes of field research. Third, the definition talks about the "formulation of laws," but supposedly laws already exist in nature and we are just discovering them. Furthermore, it's not clear whether theory is part of science, but without its inclusion, how can we justify, for instance, theoretical physics, which is considered a very important and indispensable branch of this discipline.

Let's take another typical example. Andersen and Hepburn (2016), in their entry entry for the scientific method in The Stanford Encyclopedia of Philosophy state: "Science was seen to embody the most successful form of reasoning (but which form?) to the most certain knowledge claims (but how certain?) on the basis of systematically collected evidence (but what counts as evidence and, in particular, should the evidence of the senses or rather of rational insight take precedence?)" Again, several pertinent questions and queries seem in order here: Exactly which form of reasoning are we referring to here? How do we determine certainty of knowledge claims? What counts as systematically collected evidence? I can confidently argue that one of the most systematically collected bodies of evidence is the data collected by the General Social Survey, which is designed and carried out bi-annually by the National Opinion Research Center out of the University of Chicago. It is based on a very rigorous and tested methodology including multi-stage random sampling and strict and systematic procedures that produce one of the most representative data sets about the U.S. population on a variety of variables, such as demographics, opinions, views, affiliations, etc.

There are at least two other problems with current definitions of science. The first is cultural differences in the understanding of what science is. In the U.S. and UK, the conceptualization of science and the scientific method, as well as the terminology and colloquialisms, are anchored exclusively in the principles of Positivism. This in effect restricts science and the scientific to the Positivist paradigm and to the natural sciences. One consequence of this is that other paradigmatic traditions are overlooked. The articles on science on Wikipedia are interesting examples of conceptual and terminological differences about science in different cultures. They provide information about how in different cultures science is conceptualized differently. Currently it is easy to read articles in different languages using the Translate option of Wikipedia or the browser. However, when translated from German and French into English, there is no direct concept for the HUMANITIES as those academic disciplines which study the human condition using methods that are largely analytic, critical, or speculative, as distinguished from the mainly empirical approaches of the natural and social sciences. So, the Geisteswissenschaften, still 
sciences in German, become Humanities (still non-sciences) in the English translation. The French for humanities, sciences humaines, in the English translations becomes Humanities and loses the direct reference to science. A closer interpretation of the original German definition will be that "the human sciences are those academic disciplines which study the human condition using methods that are largely analytic, critical, or speculative, as distinguished from the mainly empirical approaches of the natural and social sciences. Conventionally the humanities include the classics, languages, literature music, philosophy, history, religion, and the visual and performing arts. Additional subjects sometimes included in the humanities are anthropology area studies, communications and cultural studies, although these are often regarded as social sciences (Wikipedia). In short, both in German and French, the human sciences are considered a type of science.

The second problem is the exclusion from the typical definitions of science as a social institution. Social institutions include the constellation of activities, groups, organizations, and traditions that serve to fulfill an important need for society. Sociology of science has studied it as an institution for quite some time now. The point is that restricting science and the scientific method to the Positivist paradigm in effect means overlooking other paradigmatic traditions and disregarding the concept of science as an institution. By equating research results with Positivist science, the very concept of paradigm is neglected. However, if science is conceptualized as a social institution with the purpose of knowledge production, and if we accept the notion of paradigm, then other paradigms can easily be incorporated within the scientific realm. Such an approach will emancipate excluded paradigms. This way of thinking will provide solid ground for justifying, for example, the use of qualitative paradigms and for accepting their utility in making important discoveries about human groups, cultures, and societies.

\section{The Two Cultures Divide}

The prevalent concept of science as represented in the traditional definitions naturally leads to a sharp contrast between the natural sciences and the humanities, with the social sciences typically being lumped together with the humanities. This juxtaposition has existed for some time. Initially, the only form of scientific activity was the so-called "natural philosophy." The study of the human condition, or the socalled "humanities' then became institutionalized in the disciplines of philosophy, religion, music, and art. Later on, the so-called "natural sciences" developed as somewhat autonomous disciplines, such as physics, astronomy, medicine, biology, chemistry, mathematics, some areas of engineering (although those were later classified as applied science or technology). The so-called "social sciences" emerged

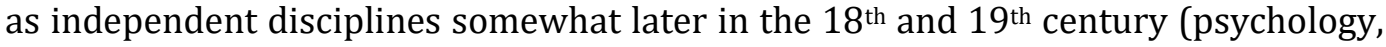
economics, political science, sociology, anthropology). Thus, the separation between the "hard sciences"(natural science) and the "soft sciences"(humanities and social sciences) took shape in the $19^{\text {th }}$ century and under the positivist aegis continued 
throughout the $20^{\text {th }}$ century and into the present, although the concept of the "two cultures" was only articulated by the British scientist and writer C.P. Snow in the 1950s. In the famous 1959 Rede Lecture, Snow $(1959,1993)$ argued that Western science and humanities have developed as two separate and incompatible areas of intellectual endeavor that do not know or care much about each other and this lack of communication or cooperation impedes the solution of world's problems.

As the British intellectual put it: "Literary intellectuals at one pole-at the other scientists, and as the most representative, the physical scientists. Between the two a gulf of mutual incomprehension-sometimes (particularly among the young) hostility and dislike, but most of all lack of understanding. They have a curious distorted image of each other. Their attitudes are so different that, even on the level of emotion, they can't find much common ground." (Snow 1959, p. 2).

Snow acknowledges that the stubbornness of the "two tribes" in pursuing only their narrow interests and largely ignoring the second aspect of intellectual creative activity does not come without consequences for society and is not purely academic. He points out that "This polarisation is sheer loss to us all. To us as people, and to our society. It is at the same time practical and intellectual and creative loss, and I repeat that it is false to imagine that those three considerations are clearly separable." (Snow 1959, p. 6).

The British author seems to recognize that this had deteriorated in that regard in the previous 20 years or so and writes in regards to asking, for example, literary men to describe the Second Law of Thermodynamics: " The response was cold: it was also negative. Yet I was asking something which is about the scientific equivalent of Have you read a work of Shakespare's?

I now believe that if I had asked an even simpler question-such as, What do you mean by mass, or acceleration, which is the scientific equivalent of saying, Can you read? - not more than one in ten of the highly educated would have felt that I was speaking the same language. So the great edifice of modern physics goes up, and the majority of the cleverest people in the western world have about as much insight into it as their neolithic ancestors would have had." (Snow 1959, p. 8).

C.P. Snow further makes several important points. One is that the British system of education needs to be overhauled to become more general and not so specialized. Another keen observation is that there are whole branches of science that are not treated with the respect they deserve when we stick to the dichotomy "science versus humanities" by boxing them into classifications they themselves disagree with. For example, engineering and applied science are regularly regarded as poor cousins of the natural sciences, although they are considered as part of those. Similarly, the social sciences are lumped together with the humanities and not considered as distinct and specific intellectual domains that have their own subject matter and their own methods of research, as well as their own theories and autonomous institutional 
entities with a particular subculture. Perhaps the most serious clash between the two cultures happened during the so-called "Science Wars."

\section{The Science Wars}

The term refers to a particularly contentious and acerbic confrontation between the natural sciences and the humanities/social sciences, which happened in the early 1990s. We have described this episode in the recent history of science in detail elsewhere (Chompalov \& Popov, 2014), but will recap the main events and their implications in this section. For a long time, the two cultures largely ignored each other and focused on their own goals and objectives without much communication or even an attempt to examine let alone criticize one another. But this situation dramatically changed in the 1990 s.

Two developments are probably responsible for the turn from being "polite strangers" to engaging in full-blown hostilities. One was probably the diminished funding by the government of the natural sciences and the changing mix of this funding. As the $20^{\text {th }}$ century came to a close, American research and development spending reached $\$ 205.7$ billion in 1997, up from $\$ 74.3$ billion in 1960 (calculated in 1997 dollars to take account of inflation). During the same period, however, industry's share of spending rose from $33 \%$ to $65 \%$ of the total expenditures for R\&D, while the government's share fell from $66 \%$ to $31 \%$. Furthermore, more government funding went to the life sciences at the expense of a reduced share for the physical sciences. Physicists were not thrilled with this change, since they have largely been responsible for winning World War II and for the economic prosperity in the postwar period. The second development concerned a noticeable turn in the study of science from positivism to constructivism and the devaluation and debunking of some long held beliefs in the objectivity, superiority, and omniscience of the natural sciences and in particular physics and allied sciences. When this initial quiet development in an esoteric field (Science and Technology Studies), populated almost exclusively by humanists and social scientists, became more and more publicized and started affecting the reputation of and support for the hard sciences, the latter finally took the gloves off and the war was on.

As was already pointed out, the emergence of the social studies of science is associated with the research of Robert Merton $(1970,1973)$ who used a positivist model to study science itself. Examining the institutionalization of natural science in $17^{\text {th }}$ century England with the establishment of the Royal Society and subsequent developments, Merton (1973) concluded that science is perceived as a rational enterprise, in which the content of the natural scientific knowledge is ultimately determined by facts. There are clear lines of demarcation between science and nonscience, with the main one being that science provides verifiable and highly valid knowledge based on the scientific method and reflection of objective reality, knowledge that is cumulative and reliable. Sociology, however, has a role to play outside of the content of science and that is to study its social aspects, such as its 
organization, science as a social institution, its relationships with other social institutions, and other "external conditions."

Science, argued Merton (1973), turns out to be a very logical and well-organized enterprise, which exercises social control over the scientific community by adhering to the "scientific ethos." The latter consists of the already mentioned four social norms guiding scientists' behavior: 1) "Communism," which asks scientists to share their findings with the scientific community so that the institution promises 'returns' only on 'property' that is given away; 2) "Universalism" enjoins scientists to evaluate knowledge claims using universal and impersonal criteria, so that the allocation of rewards and resources should not be affected by the contributor's race, gender, nationality, social class, or other functionally irrelevant statuses; 3) "Disinterestedness" suggests that the primary motive for scientists to do research should not be self-interest because such un-altruistic behavior would conflict with the institutional goal of science (extending certified knowledge); 4) "Organized Skepticism" proscribes dogmatic acceptance of claims and instead urges suspension of judgment until sufficient evidence and argument are available. So long as scientists observe and honor this "moral code," science will function smoothly and be able to achieve its major goals of producing valid and reliable knowledge, which has important practical applications (Merton, 1973).

The tension between the two cultures rose substantially in the early 1990s with a reorientation of social studies of science toward a more critical examination of how scientists create knowledge and how social factors affect this process. Thus, it was not until the so-called "constructivist and interpretivist turn in social studies of science" that severe criticisms and rejection were voiced by a number of natural scientists that eventually culminated in the "science wars." The turn itself happened in the 1970s and was jumpstarted by several ideas in philosophy and history of science, such as the falsification theory of K. Popper (2002) and the "epistemological anarchism" of P. Feyerabend (1975).

However, the biggest impetus for the "constructivist turn" came from the historian of science Thomas Kuhn, whose seminal book "The Structure of Scientific Revolutions" (1970) sent shock waves through the field of social studies of science (Chompalov \& Popov, 2014). Terms such as "paradigm," "incommensurability," "normal science", "scientific revolution," "scientific anomaly", "scientific crisis," "scientific puzzlesolving", and so on became common in social studies of science and his views have reshaped the field, especially his ideas that science progresses not by systematic accumulation of verifiable knowledge but by abrupt interruptions, paradigm shifts, knowledge claims being relative and incommensurable, that different scientific communities can have diametrically opposed interpretations of the same data, that all data are theory-laden. A number of science studies theories and approaches were stimulated by this new paradigm: postmodernist critiques, feminist approaches, the strong programme, relativism, discourse analysis, laboratory constructivist studies, 
reflexivity, and so on (Collins, 1981; Gilbert \& Mulkay, 1984; Latour \& Woolgar, 1979; Woolgar, 1988). What they have in common is the argument that science is a social construct, including scientific discoveries and theories, and should therefore not enjoy privileged epistemological status; scientific reasoning is just another form of discourse; nature and reality is what scientists agree to call natural and real. In a lot of ways this is perceived as challenging science's authority, debunking scientific "myths," cutting science down to size, and arguing that science is no more objective than any other human creative activity (Kuhn 1970).

This constructivist turn did not go unnoticed by natural scientists. A number of them, such as Gross and Levitt (1994), Sokal and Brichmont (1999) (Sokal of the famous or infamous "Sokal's hoax"), and Weinberg (1995) launched a scathing campaign of severely criticizing the new turn in social studies of science for being shoddy scholarship, incompetence about the scientific discoveries they are writing about, a political attempt to undermine objectivity and hence the authority and reputation of science, spreading nonsense and confusing claims about science, and so on. Perhaps the most serious attacks on science and technology studies came from Gross and Levitt (1994) in their provocatively titled book "Higher Superstition" where they dismissed "the relativism of the social constructivists, the sophomoric skepticism of the postmodernists, the incipient Lysenkoism of feminist critics, the millennialism [sic] of the radical environmentalists, the radical chauvinism of the Afrocentrists" as "unscientific and antiscientific nonsense, a bizarre war against scientific thought and practice being waged by the various strands of the academic left" (Gross \& Levitt, 1994, pp. 252-253). In a later article Gross and Levitt (1995) hurl another accusation towards the constructivists and postmodernists, one of the most damaging sins anybody can commit in academia-incompetence and intellectual laziness. They argue that the guiding and main motives of the new "left anti-science warriors" is shying away from serious criticism based on understanding science in depth. Instead, the new postmodern critique becomes so appealing to its proponents, because it does not require anyone to master science., an activity that's fashionable and spreading as an easy way to make a career by engaging in lazy academics, inspired by a specific "cultural left" ideology that is profoundly hostile to natural science (Gross \& Levitt, 1995).

The other side replied by accusing natural scientists of arrogance, deception, unwillingness to examine honestly alternative accounts, and so on. In a number of chapters in the edited volume "Beyond the Science Wars," edited by Segerstrale (2000), sociologists, historians, and philosophers who represent the constructivist/interpretivist trend in Science and Technology Studies (STS) tried to respond to the criticism by natural scientists. One reply is that scientists mischaracterize constructivism by labeling it "anti-scientific" and incompetent. Actually, about half of the authors in the volume have a science background. Furthermore, constructivism does not represent the whole field of STS, although it is clearly the dominant trend. More than $75 \%$ of scholars in the field and more than 
$80 \%$ of the articles in the top journals in the field (Social Studies of Science and Science, Technology, and Human Values) belong to some brand or reincarnation of social constructivism. Nonetheless, there are still about a quarter of articles and books that use quantitative methods of research and employ a modern-day positivist approach to systematically study science as a social institution in the vein of Merton's legacy. This research has largely been ignored by the natural scientists.

An additional dissatisfaction of constructivists is that scientists used methods that would be totally unacceptable in physics, chemistry, or biology to try to discredit their opponents. Thus, the "Sokal Hoax" deliberately used deception and misrepresentation to try to publish something nonsensical about the theory of relativity and quantum theory in order to prove lax academic standards at the leading postmodernist journal Social Text. He succeeded and the article was indeed published as an example of how even a modern-day physicist can productively embrace postmodern theory to analyze developments in his own field. Sokal proved his point, but the methods he used were shaky and unscientific and surely involved deception. Social constructivists also object to their misrepresentations by natural scientists as leftist ideologues out to demolish science, as modern day Luddites, as incompetent when they are simply being controversial, etc.

The controversy still continues, although in the past decade or so the intensity of the debate has been somewhat toned down. The potential for it flaring up again, however, is still there. What is important to point out here is the context within which the Science Wars erupted. Up until the 1990s there was little interest or desire to engage on the part of the natural scientists, who regarded STS as an oddity that does not deserve their time and attention. By the early 1990s, however, the political, social, and funding context has changed unfavorably. Budgetary restrictions and pressure to engage more in teaching and less in research have alarmed many working natural scientists. Scientists have also been pressured to revise their ethics. Disturbing examples of the diminished role of natural science in the early 1990s were the closing down of the project to build a Superconducting Supercollider in Texas in 1993, or the setback in seeing diminished funding and support for NASA, or the closing of OTA, Congress's Office of Technology Assessment. As natural science has tried to push back and defend itself, it is quite possible that critics of science will face a stronger backlash, given the still formidable position that science occupies in society.

\section{The Need for Integration: The Social Sciences as a Natural Bridge between the Two Cultures}

The preceding discussion reveals that the current situation of the two cultures still remaining in their silos and unwilling to focus on a productive dialogue is highly unsatisfactory. The Science Wars only exacerbate an already tense situation especially in view of diminishing resources for both the natural sciences and especially the humanities and the social sciences. The changing of priorities in support and investment toward more applied science and immediate results puts an 
additional strain on the relationships between the two cultures. The untenable common definition of science from a Positivist view needs to be modified to include any systematic effort that contributes to the body of knowledge and our understanding of phenomena that pertain to the natural world, the social world, and human nature. Instead of continuing turf wars and attempts to highlight the shortcomings of the other 'culture' the two cultures need to emphasize the positive contributions of each other and how this creates opportunities for cooperation and synergies.

This state of affairs is even more puzzling, since today the need for integration is greater than ever. The main reason is that most problems, especially global problems, are multifaceted and do not lend themselves to a simple, unidisciplinary solution. We already gave the example of global warming, which has multiple aspects that need to be addressed by a collective scientific effort (and that includes the social sciences and the humanities) in order for the policy recommendation to be successful. Chemical, biological, and physics analyses are definitely needed and essential to understand the mechanisms and consequences of our changing environment due to global warming. Meteorology has an important role to play by examining shifting climate patterns and what this entails. Urban planning (itself an interdisciplinary field) becomes a necessary part of these studies. The social sciences and humanities can also contribute to the solution in multiple ways. As is already happening, poorer communities in Third World countries are being displaced, and migration has also intensified due to more frequent and more severe natural disasters caused by global warming. Psychologically, it is also very challenging to deal with growing uncertainty, as well as with loss of life and property. Whole communities are uprooted and exposed to hardship and suffering. Crime in these areas affected by natural disasters is on the rise. Of course, there is also a tremendous price to pay financially and in terms of social instability, hunger, and loss of security.

Another appropriate example is the current global Coronavirus pandemic. A lot of mistakes could have been avoided if there was an interdisciplinary field dealing with possible epidemics and pandemics. The problem again has multiple aspects that needed to be addressed early on via cooperation among multiple disciplines instead of disparate ad hoc efforts to react to already unfolding events, which we were ill prepared to anticipate or react quickly to. Biology, especially virology and immunology, have improved our understanding of the genetic structure of COVID-19, how it affects the body, why it causes a more severe reaction in certain people, how many strands of the virus exist, etc. Immunology and pharmacology are working very hard to come up with an effective vaccine against the virus, while epidemiologists have identified the mechanisms of infection and transmission, the rate of spread of the disease in human populations, the rate of mortality, and so on.

But there are also important social and humanitarian aspects. One is the effect on the economy and how different countries deal with the economic impacts of the 
pandemic. There is little doubt that we might be headed to another global recession. Certain industries have been devastated by the pandemic and some businesses may never recover (the hospitality industry, travel, restauranteurs, a number of small businesses). Others will be drastically changed (education, health care). Most people's financial savings will be wiped out. There are a lot of other economic implications from the pandemic, which depend on how long it will last and how many people it will ultimately affect. The speed of economic recovery, although hard to estimate now, becomes crucial.

Then you have all the political implications and changes that are brought about by the COVID-19 pandemic that political scientists and sociologists have to be cognizant of and study. Then you have the social and human dimensions of the pandemic. The psychological effects are also worth studying-dealing with the loss of a loved one and grief, added stress, increased mental problems, the effects of the lockdown and quarantine on people's psyche and moods, etc. Interestingly enough, there have been some unintended positive consequences. With less travel and use of motor vehicles we are witnessing cleaner air and less pollution. Also, the price of gasoline went down, which relieved the financial woes of millions of people.

All this points to a pressing need for more research integration and collaboration between the two cultures. One way this is happening on a modest scale is through interdisciplinarity. This, however, has been and still is pretty modest and incremental. Apart from the slow pace of the formation and functioning of interdisciplinary areas, another problem here is that it almost always occurs either within the natural sciences or within the humanities and social sciences but rarely across the two cultures. Thus, in the natural sciences we have biotechnology, biochemistry, physical chemistry, cheminformatics, environmental science (an interdisciplinary academic field that draws on ecology, geology, meteorology biology chemistry engineering, and physics to study environmental problems and human impacts on the environment). On the other hand, in the social sciences and humanities the interdisciplinary areas are cultural studies, religious studies, women's studies, urban studies, media studies, environmental studies (which studies human interaction with the environment from the point of view of ethics, geography, anthropology, policy politics, urban planning, law, economics, philosophy sociology and social justice, planning, pollution control and natural resource management). Rarely do we encounter a cross between the two cultures and these efforts have not been very successful (e.g., sociobiology). Apparently, we can all benefit as a society if we encourage and sponsor the growth of interdisciplinary fields that would involve cross-fertilization between the natural sciences, engineering, the social sciences, and the humanities.

One obvious bridge between the sciences and the humanities are the social sciences. They embody aspects of both and have the propensity to bring the two cultures together in a natural fashion. Take, for example, sociology. It definitely uses rigorous 
quantitative methods just like the natural sciences. As a matter of fact the majority of current sociology employs some form of quantitative empiricism. The bulk of research published in the major sociological journals involves surveys, experiments, meticulous observation as methods of research and very sophisticated mathematical and statistical techniques to carry out the analysis and hypothesis testing (multiple linear regression, regression over space and time, logit and probit models, event history analysis, LISREL, log-linear analysis, factor analysis, and so on). But important specialties with sociology as a discipline also favor qualitative methods of research, constructivist and interpretivist theories, postmodernist ideas, ethnomethodology, cultural analysis, and similar tools of inquiry. Economics, political science, psychology, and communications studies exhibit the same fusion of quantitative and qualitative research methods and theorizing.

\section{Concluding Remarks}

We have so far tried to make a case for why current definitions of science do not pass muster and why the continual separation and animosity between the two cultures culminating in the so-called Science Wars are highly unproductive and harmful, especially in the current political environment. This is puzzling in view of diminishing public support for science, the spread and popularity of anti-scientific attitudes, and the dwindling government funding for scientific research and development. In anything, the sciences need to join forces and act together, as, to quote the old adage, "united we stand, divided we fall." Yes just the opposite seems to be taking place.

The accepted definitions of science exclude large areas of the humanities and social sciences by favoring the outdated Positivist thinking that only investigations of the natural world based on observations and experiments should count as scientific activity. The exclusively narrow interpretation of scientific evidence is largely due to the misconception about the "true" nature of science. In some countries and cultures, the conceptualization of science and the scientific method, as well as the terminology and colloquialisms, are anchored exclusively in the principles of Positivism. This in effect restricts science and the scientific to the Positivist paradigm. One consequence of this is that other paradigmatic traditions are overlooked. By equating research results based on the scientific method as applied to Nature with science, the very concept of paradigm is neglected.

However, if science is conceptualized as a social institution with the purpose of valid and reliable knowledge production, and if we accept the notion of paradigm, then other paradigms can easily be incorporated within the scientific realm. Such an approach will emancipate the excluded paradigms and such a way of thinking will provide solid ground for justifying the use of qualitative paradigms and for accepting their utility. The acceptance of the scholarly work in the humanities as a science will facilitate the acceptance of the paradigms in the humanities on par with Positivistm. This in turn will enrich the methodological options of a number of sciences and will allow for more productive interdisciplinary communication and collaboration. 
Viewing science as a social institution will facilitate the understanding of what we call today Humanities and social sciences as knowledge production systems that provide high quality knowledge about the social world, cultural phenomena, and the human psyche. This high quality knowledge will be properly appreciated and used in program planning, event planning, and the design of activities and social situations. The perception of Humanities as sciences will also foster a more reflective and traceable approach to knowledge and the scholarly designs. The mediation between current sciences and humanities will allow us to clear many terminological problems, inconsistencies, and artificial differentiations. It will help understand better the relationships between theory and field research, basic and applied sciences, and the relationships of all of these to the technical/engineering sciences.

Social institutions can be viewed as activity systems as well. This provides a link between the activity and the institutional approaches of analysis. From an activity theory perspective, science can be construed as a system of activities. The subdivisions of science are currently the disciplines. We can see science in general as a system of activities or disciplines, separated, yet related to some degree. But in the current climate of interdisciplinary research, we can see science as a constellation of activities that complement each other. In interdisciplinary research we clearly need to interface those different activities in a way that they (or their agents) can communicate successfully, understand each other, evaluate each other's input and data, as well as accept and use the data and ideas offered by the other.

This can form the basis of an earnest effort for more integration of the two cultures and for achieving much needed synergisms to tackle complex problems that tend to be multifaceted and whose solutions do not easily conform to single disciplinary paradigms. The contention here is that such a bridge between the two cultures can use as a model the social sciences, since they successfully combine methods from the natural sciences with approaches common in the humanities. This is clearly one feasible path to both greater interdisciplinarity and more vigorous collaboration between the different branches of science that can benefit both working scientists and society at large when dealing with pressing issues like environmental problems, the depletion of natural resources, pandemics, and natural disasters.

\section{References}

[1] Andersen, H., \& Hepburn, B. (2016). Scientific method. In Edward N. Zalta (Ed.), The Stanford Encyclopedia of Philosophy (Summer 2016 Edition), [Online] Available (June 08, 2020) https://plato.stanford.edu/archives/sum2016/entries/scientific-method/

[2] Chompalov, I., \& Popov, L. (2014). Sociology of science and the turn to social constructivism. Social Sciences 3(2), 59-66. doi: 10.11648/j.ss.20140302.14

[3] Collins, H. (1981). Stages in the empirical programme of relativism. Social Studies of Science, 11, 3-10. https://doi.org/10.1177/030631278101100101 
[4] Collins Online English Dictionary. [Online] Available (June 08, 2020), https://www.collinsdictionary.com/dictionary/english/science.

[5] Feyerabend, P. (1975). Against method. Atlantic Highlands, NJ: Humanities Press.

[6] Gilbert, G., \& Mulkay, M. (1984). Opening pandora's box: A sociological analysis of scientists' discourse. Cambridge, UK: Cambridge University Press.

[7] Gross, P., \& Levitt, N. (1994). Higher superstition: The academic left and its quarrels with science. Baltimore, MD: Johns Hopkins.

[8] Latour, B., \& Woolgar, S. (1979). Laboratory life: The construction of scientific facts. Princeton: Princeton University Press.

[9] Kuhn, T. (1970). The structure of scientific revolutions. Chicago: University of Chicago Press.

[10] Merton, R. (1970). Science, technology, and society in seventeenth-century England. New York: Howard Fertig.

[11] Merton, R. (1973). The sociology of science. Chicago: University of Chicago Press.

[12] Parsons, K. (Ed.). (2003). The science wars: Debating scientific knowledge and technology. Amherst, NY: Prometheus Books.

[13] Popper, K. (2002). Conjectures and refutations: The growth of scientific knowledge. London: Routledge.

[14] Segerstrale, U. (Ed.). (2000). Beyond the science wars: The missing discourse about science and society. Albany, NY: State University of New York Press.

[15] Snow, C. P. (1959). The Rede Lecture. [Online] Available (June 08, 2020) http://m.s-f-walker.org.uk/pubsebooks/2cultures/Rede-lecture-2cultures.pdf

[16] Snow, C. P. (1993). The Two Cultures. Cambridge: Cambridge University Press.

[17] Sokal, A., \& Bricmont, J. (1999). Fashionable nonsense: Postmodern intellectuals' abuse of science. New York: Picador USA.

[18] Weinberg, S. (1995). The methods of science ... and those by which we live. Academic Questions, 8(2), 7-13. https://doi.org/10.1007/BF02683184

[19] Woolgar, S. (Ed.). (1988). Knowledge and reflexivity: New frontiers in the sociology of knowledge. London: SAGE. 